\title{
PERCEPÇÕES DE ESTUDANTES DA REDE PÚBLICA E PRIVADA ACERCA DA MAIORIDADE PENAL
}

\author{
STUDENTS PERCEPTIONS OF PUBLIC AND \\ PRIVATE SCHOOLS ABOUT CRIMINAL MAJORITY
}

Kay Francis Leal Vieira' Elaine Amorim Quirino²

\section{RESUMO}

A maioridade penal define a idade mínima pela qual o sistema judiciário pode processar um cidadão. A legislação brasileira entende que o menor de 18 anos deve receber tratamento diferenciado, pois encontra-se no processo de construção do "eu". No cenário atual propõe-se a redução dessa maioridade penal para os 16 anos, para que o adolescente seja processado e julgado como um adulto. Diante disso, objetivou-se analisar a percepção de adolescentes estudantes da rede pública e privada acerca da maioridade penal. Tratou-se de uma pesquisa de campo, descritiva e de natureza quantitativa e qualitativa, realizada em duas instituições de ensino, sendo uma pública e uma particular, localizadas em João Pessoa - PB. A amostra foi composta por 70 adolescentes, sendo 35 de cada instituição, que responderam um questionário contendo dados sociodemográficos, analisados através do pacote estatístico SPSS e questões abertas que foram submetidas à análise de conteúdo temático. Os resultados apontaram que a maioria dos adolescentes de ambas as escolas é favorável ao projeto de redução. Divergências, entretanto, foram constatadas no grupo que assumiu postura contrária à redução. Entre os estudantes da rede pública emergiu a hipótese de agravamento da situação, onde os adolescentes iriam se especializar na escola do crime. Os estudantes da rede particular, por sua vez, avaliaram o sistema prisional e seus meios de ressocialização como inadequados, considerando a falta de maturidade que é caraterística da adolescência. Conclui-se que oferecer melhoria em políticas públicas a favor desses jovens se torna uma saída para afastá-los da prática de atos ilícitos.

Palavras-chave: Adolescência. Maioridade Penal. Percepção.

\section{ABSTRACT}

The criminal majority sets the minimum age at which the legal system can process a citizen. The Brazilian law considers that the under 18 years should receive differential

1 Doutora em Psicologia Social pela Universidade Federal da Paraíba (UFPB). Docente do Centro Universitário de João Pessoa (UNIPÊ). E-mail: kayvieira@yahoo.com.br

2 Graduada em Psicologia pelo Centro Universitário de João Pessoa (UNIPÊ). E-mail: elaine_amorim81@hotmail.com

\section{INTER/SCIENTIA}

REVISTA INTERSCIENTIA | V. 7 | N. 1 | P. 140-161 | JAN-JUN/2019 
treatment, it is in the process of building the inner self. In the current scenario is proposed to reduce this criminal responsibility to 16 years, for adolescents to be processed and judged as an adult. Against, aimed to analyze the perception of adolescents students of public and private school about criminal majority. This was a field survey, descriptive and quantitative source and qualitative, held in two schools, one public and one private, located in the city of João Pessoa-PB. The survey was composed of 70 adolescents, being 35 of each institution that answered a questionnaire containing sociodemographic characteristics, analyzed by the statistical package SPSS and open questions that were submitted to the thematic content analysis. The results showed that the majority of the adolescents of both schools are in favor of the reduction project. Divergences, however, were found in the group that took a stance contrary to the reduction. That those who took a opposite posture, among public school students emerged the hypothesis worsening the situation where teenagers would specialize in criminal school. So the students in private schools consider the prison system and their rehabilitation means inadequate, and also noticed the lack of maturity which includes adolescence. Concludes that offer improvement in public policies in favor of these young people becomes an opportunity to away them o illicit behavior.

Keywords: Adolescence. Criminal majority. Perception.

\section{INTRODUÇÃO}

Frente aos altos índices de violência e criminalidade constatados em diversas esferas do contexto nacional, a discussão sobre a redução da maioridade penal vem ganhando destaque. A maioridade penal ou maioridade criminal define a idade mínima a partir da qual o sistema judiciário pode processar um cidadão como uma pessoa que se responsabiliza por seus atos. Atualmente, a legislação brasileira entende que o menor de 18 anos deve receber tratamento diferenciado daquele aplicado ao adulto, alegando que o mesmo ainda se encontra em processo de desenvolvimento, não apresentando maturidade suficiente para responder por seus atos.

No cenário atual existe um grande movimento envolvendo o poder público

e a sociedade civil sobre a redução dessa maioridade penal. A proposta seria rebaixar para 16 anos a responsabilidade do jovem sobre seus atos infracionais, para que este seja processado e julgado como um adulto. Segundo Vavassori e Toneli (2015), a movimentação social e política a partir das Propostas de Emendas Constitucionais (PECs) sugerem a redução da maioridade penal, aquecendo as discussões sobre responsabilização e as demandas por controle e repressão da criminalidade juvenil. 
A Proposta de Emenda à Constituição (PEC) 33/2012 de autoria do senador Aloysio Nunes Ferreira (PSDB-SP) foimotivo de efusivos debates no Congresso Nacional. O texto abria a possibilidade de a Justiça aplicar, a adolescentes envolvidos em crimes como homicídio qualificado; extorsão mediante sequestro; e estupro, penas impostas hoje a criminosos adultos. Entretanto, apesar de ter sido extensamente debatida na Comissão de Constituição, Justiça e Cidadania (CCJ), a proposta não chegou a ser votada na comissão e foi arquivada no final de 2018. Porém, na primeira sessão deliberativa de 2019, foi apresentada mais uma proposta, a PEC 04/2019, de autoria do senador Marcio Bittar, que propõe a redução da maioridade penal para os 16 anos, sem exceção. Altera a redação do art. 228 da Constituição Federal, argumentando a necessidade de adequar a idade de inimputabilidade penal à nova realidade demográfica brasileira e combater a criminalidade.

\section{A CONSTITUIÇÃO DO SUJEITO ADOLESCENTE: ASPECTOS PSICOSSOCIAIS}

A adolescência se caracteriza como uma complexa transição da infância para vida adulta, sendo também um perío do decisivo na formação do caráter do indivíduo. Essa fase pode ser visualizada sob duas perspectivas: uma de caráter cronológico e outra de domínio social. A perspectiva cronológica, a caracteriza como um processo de mudanças biopsicossociais, compreendendo a faixa etária dos 10 a 19 anos, indicada pela Organização Mundial de Saúde - OMS (2014), ou de 12 a 18 anos, de acordo com o Estatuto da Criança e do Adolescente - ECA. Sob a perspectiva social, a adolescência inicia-se com as mudanças corporais da puberdade e termina com a inserção social, profissional e econômica na sociedade adulta (FORMIGLI; COSTA; PORTO, 2000).

De acordo com Vaz e Moreira (2015), a fase da adolescência é o momento em que os jovens estão adquirindo um sistema pessoal de valores e constituindo uma visão de mundo através de suas próprias concepções. Ressaltam ainda que esta construção se estabelece a partir dos aprendizados advindos de experiências significativas do seu processo de desenvolvimento.

Estudos importantes sobre o desenvolvimento humano, como os de Sigmund Freud (1905/1989) e Erik Erikson (1987) explicam através de suas teorias, como se dá a formação da identidade dos adolescentes. Freud dividiu as etapas do desenvolvimento em cinco, denominando-as de fases psicossexuais: (1) fase oral (primeiro ano de vida), (2) fase anal (do primeiro ao terceiro ano de vida), (3) fase fálica (dos três aos cinco anos de vida), (4) fase de latência (estende-se até a puberdade) e (5) fase genital (durante toda a adolescência e se estende até a vida adulta). Ao fim da terceira fase então, por volta dos cinco anos de idade, o núcleo da personalidade do indivíduo estaria essencialmente formado. Segundo Freud, atingir a fase genital é fundamental para se chegar ao pleno desenvolvimento 
biopsicossocial e intelectual de um adulto, nela está constituído o ego, e com ele o senso de responsabilidade, normas e regras.

O estudo de Veríssimo (2002) relata a importância das interações psicossociais no desenvolvimento do ego em relação à personalidade, afirmando que o ambiente tem seu papel decisivo na construção dos indivíduos. De acordo com esse autor, as fases da infância e adolescência tratam-se de momentos significativos, uma vez que o indivíduo se prepara para constituir-se como sujeito e posteriormente integrar e assumir os papéis sociais.

Erikson (1987) optou por distribuir o desenvolvimento humano em oito fases, que correspondem a conflitos: (1) Confiança $X$ Desconfiança (até um ano de idade); (2) Autonomia X Vergonha e Dúvida (segundo e terceiro ano); (3) Iniciativa $X$ Culpa (quarto e quinto ano); (4) Construtividade $X$ Inferioridade (dos 6 aos 11 anos); (5) Identidade $X$ Confusão de Papéis (dos 12 aos 18 anos); (6) Intimidade $X$ Isolamento (jovem adulto); (7) Produtividade $X$ Estagnação (meia idade) e (8) Integridade $X$ Desesperança (velhice). A sua teoria, chamada de Desenvolvimento Psicossocial, desvia o foco fundamental da sexualidade para as relações sociais. A cada etapa, o indivíduo cresce a partir das exigências internas de seu ego, mas também das exigências do meio em que vive, sendo, portanto essencial a análise da cultura e da sociedade em que vive o sujeito em questão.

Erikson considera a adolescência como a fase mais crítica do ciclo vital, afirmando que um indivíduo constrói a sua personalidade durante essa etapa, porém essa construção não acontece do mesmo modo para todos os adolescentes, ou seja, de um modo padronizado e linear. Durante esta fase da vida surgem crises, indecisões e situações conflituosas que precisam ser resolvidas. Cada conflito superado significa dizer que o indivíduo está alcançando um bom desenvolvimento.

Para Chiuzi, Peixoto e Fusari (2001), no quinto estágio desta teoria o adolescente vai adquirir uma identidade psicossocial, isto é, compreender a sua singularidade, o seu papel no mundo. O jovem experimenta uma série de desafios que envolvem suas atitudes para consigo, com seus amigos, com pessoas do sexo oposto, amores e a busca de uma carreira e de profissionalização.

A partir da criação do Estatuto da Criança e do Adolescente (ECA, 1990), esse público passou a ser reconhecido como sujeito de direitos garantidos por uma legislação específica, que os considera como cidadãos. Embora na prática nem sempre isso ocorra, o ECA preconiza que as crianças e os adolescentes brasileiros devem ser protegidos pelo Estado, pela sociedade e pela família de maneira integral. O Conselho Nacional dos Direitos da Criança e do Adolescente (CONANDA), criado em 1991, se torna responsável por deliberar sobre a política de atenção à infância e à adolescência, assumindo o papel normatizador e articulador com os demais atores do Sistema de Garantia dos Direitos.

Com a instituição da Política Nacional de Juventude (PNJ), no ano de 2008, foram fundados conselhos municipais e estaduais específicos para os jovens, que se 
tornou um marco legal e que pode proporcionar aos adolescentes e a sociedade um entendimento claro sobre seus direitos e deveres para que possam se firmar diante deles. Perante todas essas conquistas, ainda observa-se que o país precisa responder aos desafios dessa política, e em especial ao enfrentamento da violência que permeia a vida dos jovens, seja ele no papel de vítima ou de violador.

\section{ASPECTOS CONSTITUCIONAIS DA MAIORIDADE PENAL}

A redução da maioridade penal é um tema, que embora não seja novo, sempre se faz presente nas polêmicas discussões na sociedade brasileira. A adolescência atualmente carrega o estigma da violência e da impunidade, havendo estudos que revelam que aproximadamente $90 \%$ da opinião pública se diz favorável ao rebaixamento da maioridade penal, fato que merece destaque no sentido de compreender os aspectos envolvidos neste posicionamento e os seus desdobramentos na instância legislativa e social (VAZ; MOREIRA, 2015).

A veiculação na mídia de crimes cometidos por adolescentes faz com que a sociedade questione e queira uma mudança nesse cenário. O Guia de Referência para Cobertura Jornalística (ANDI, 2012) referente à temática do adolescente em conflito com a lei, publicado pela Agência de Notícias dos Direitos da Infância em parceria com a Secretaria de Direitos Humanos da Presidência da República traz informações importantes relacionadas a essa problemática. Destaca que historicamente a imprensa tem contribuído para a proteção dos direitos humanos, denunciando violações e fortalecendo o debate público em torno das formas de garanti-los, porém constata que a infância e a juventude neste âmbito ainda configura um desafio. Especialmente as questões relacionadas ao adolescente em conflito com a lei encontram-se em nível preocupante de invisibilidade, uma vez que só ganham destaque na mídia quando estão associadas a crimes graves, provocando distorções na percepção pública sobre o fenômeno (ANDI, 2012).

A legislação brasileira determina que os indivíduos com idade inferior a 18 anos tenham infrações punidas conforme o art. 112 do ECA (1990). Este documento assegura que os menores de 12 anos são considerados inimputáveis, ou seja, não são passíveis de punição pelo Estado. Já os que possuem entre 12 e 17 anos recebem sanções previstas pelo Estatuto, denominadas medidas socioeducativas.

Colombarolli et al (2014) destacam que os adolescentes são encaminhados a uma Vara da Infância e Juventude e suas punições podem ser levadas a efeito com a prescrição de advertência, liberdade assistida, obrigação de reparação do dano praticado, prestação de serviço à comunidade, inserção em regime de semiliberdade ou internação em estabelecimento educacional. Estas serão aplicadas de acordo com a gravidade da infração praticada e a idade da criança ou adolescente e, além da punição, o infrator recebe apoio psicológico e participa de programas de reinserção social. 
A internação provisória e as medidas socioeducativas devem propiciar ao adolescente o acesso a direitos e às oportunidades de superação de sua situação de exclusão, de ressignificação de valores, bem como o acesso à formação de valores para a participação na vida social. Assim, a inclusão dos adolescentes pressupõe sua participação em diferentes programas e serviços sociais e públicos (SINASE, 2006).

Nota-se, portanto, que o fator predominante é o educativo e o objetivo maior das medidas socioeducativas é promover um bom desenvolvimento dos sujeitos a quem elas assistem, oferecendo uma nova visão de mundo para que lhes seja propiciado uma reconstrução pessoal. Nessa ótica, Pereira (2012) afirma que as medidas de proteção não podem ser entendidas como uma forma de castigo ou pena, e muito menos serem compreendidas como um "alívio" da responsabilidade jurídica para a criança e ao adolescente. Elas podem sofrer mudanças de aplicação, cumulando-se em outras medidas, podendo ser substituídas quando não alcançarem seu objetivo (art 99 ECA).

Nesse sentido, percebe-se que a proposta de redução da maioridade penal explana justificativas que contradizem as questões psicossociais do desenvolvimento, e dessa forma, amplia a inquietação pública. É preciso, portanto, investigar melhor as causas da violência, pois ela está diretamente ligada ao problema da maioridade, analisando como essa decisão de reduzir a idade penal para adolescentes pode transformar a vida dos jovens brasileiros.

Frente ao exposto, o presente estudo objetivou analisar a percepção dos adolescentes sobre a maioridade penal, verificando semelhanças e divergências entre os alunos da rede particular e pública de ensino. Torna-se indispensável essa discussão no meio acadêmico, sob a ótica dos adolescentes por se tratar de um segmento que é afetado diretamente pela ação, direcionando-os a uma reflexão sobre o tema e o problema da violência que atinge a toda a população.

\section{METODOLOGIA}

Este estudo trata de uma pesquisa de campo, descritiva e de natureza quantitativa e qualitativa, realizada com alunos de duas instituições de ensino, sendo uma pública e uma particular, localizadas no município de João Pessoa PB. Considerando os diferentes contextos em que vivem os adolescentes, optou-se por uma escola pública localizada em um bairro da periferia e por uma escola particular localizada em região nobre da capital paraibana.

A amostra foi do tipo não probabilística, intencional, composta por 70 adolescentes, com idades entre 14 a 17 anos, de ambos os sexos; sendo 35 de instituição pública e 35 de instituição privada. Como critérios de inclusão considerouse o fato do participante ter idade entre 12 e 17 anos (definição de adolescente segundo o ECA), estar matriculado em uma das escolas pesquisadas, desejar 
de forma voluntária participar do estudo e apresentar a autorização dos pais ou responsáveis, mediante assinatura no Termo de Consentimento Livre e Esclarecido.

O instrumento utilizado na coleta de dados foi um questionário composto por duas partes. A primeira trata dos dados sociodemográficos, contendo variáveis como: idade, gênero, escolaridade e dados socioeconômicos. Já a segunda era composta por questões elaboradas pela própria pesquisadora, de acordo com os objetivos propostos, totalizando sete questões, sendo seis fechadas e uma aberta. As questões fechadas abordavam o posicionamento dos adolescentes acerca da redução da maioridade penal, as situações em que os participantes consideravam que o adolescente já poderia se responsabilizar por seus atos e o envolvimento dos participantes com a criminalidade (se eles ou alguém conhecido já cumpriu alguma medida socioeducativa, qual o tipo de medida e por qual infração). A questão aberta, por sua vez, investigava o conhecimento que os participantes tinham acerca da proposta de redução da maioridade penal.

Após aprovação do projeto pelo Comitê de Ética em Pesquisa, a coleta de dados foi realizada nas escolas, de acordo com a disponibilidade das mesmas. $O$ processo foi realizado de maneira transparente, considerando-se todos os aspectos éticos pertinentes a pesquisas envolvendo seres humanos, de acordo com a Resolução $n^{\circ}$ 466/12. Primeiramente, os pais dos adolescentes foram convocados a assinar o Termo de Consentimento Livre e Esclarecido - TCLE. Numa próxima etapa, os alunos assinaram o Termo de Assentimento para os adolescentes, e em seguida preencheram o questionário, em sala de aula e de modo coletivo.

Os resultados do questionário sociodemográfico e das perguntas fechadas foram analisados por meio do pacote estatístico SPSS em sua versão 20.0, utilizandose da estatística descritiva. Já os resultados das questões abertas foram analisados pela técnica de Análise de Conteúdo Temática (BARDIN, 2009).

\section{RESULTADOS}

De acordo com a Tabela 1, verifica-se que a amostra foi composta, em sua maioria, por estudantes do sexo feminino (51,4 \%), com 16 anos de idade $(48,6 \%)$, que cursavam o segundo ano do ensino médio (57,1\%). De acordo com os dados, $88,6 \%$ desses adolescentes não exerciam nenhuma atividade remunerada e no tocante a renda familiar, a maioria (50\%) recebia de 2 a 3 salários mínimos.

Tabela 1: Perfil sociodemográfico dos participantes ( $N=70$ )

\begin{tabular}{l|c|c}
\hline VARIÁVEL & N & $\%$ \\
\hline Sexo & & \\
Feminino & 36 & 51,4 \\
Masculino & 34 & 48,6 \\
Idade & & \\
14 & 04 & 5,7
\end{tabular}

\section{INTER SCIENTIA}

REVISTA INTERSCIENTIA | V. 7 | N. 1 | P. 140-161 | JAN-JUN/2019 


\begin{tabular}{l|c|c}
\hline VARIÁVEL & N & $\%$ \\
\hline 15 & 20 & 28,6 \\
16 & 34 & 48,6 \\
17 & 12 & 17,1 \\
Escolaridade & 26 & 37,1 \\
$1^{\circ}$ ano & 40 & 57,1 \\
$2^{\circ}$ ano & 04 & 5,7 \\
$3^{\circ}$ ano & & \\
Trabalha atualmente & 08 & 11,4 \\
Sim & 62 & 88,6 \\
Não & & \\
Renda familiar & 13 & 18,6 \\
1 salário mínimo & 35 & 50 \\
2 a 3 salários mínimos & 16 & 22,9 \\
4 a 5 salários mínimos & 04 & 5,9 \\
6 a 10 salários mínimos & 02 & 2,9 \\
Acima de 10 salários & & \\
mínimos & &
\end{tabular}

Em conformidade ao objetivo geral deste estudo, investigou-se o posicionamento dos adolescentes acerca da redução da maioridade penal. Verificou-se, então, que, a maioria dos estudantes de ambas as escolas, responderam que são a favor, sendo $82,9 \%$ dos estudantes da escola particular e $88,6 \%$ da escola pública.

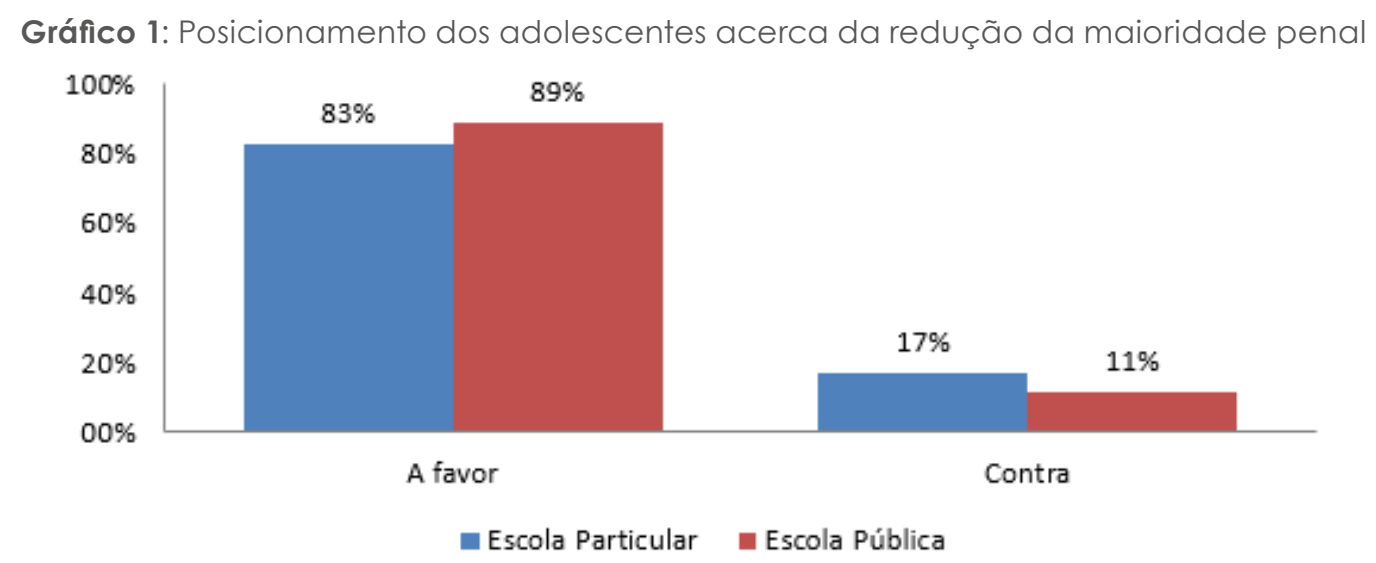

Quando indagados sobre as situações as quais os adolescentes já poderiam ser responsabilizados, a maioria dos participantes demonstraram-se contrários à obtenção da Carteira nacional de Habilitação (CNH) por adolescentes $157 \%$ dos estudantes da escola particular e 54,3\% da escola pública), e ainda demonstraram ser contra a questão de assumir uma família e ter filhos, sendo: $88,6 \%$ dos alunos da rede privada e 68,6\% da rede pública. 
Tabela 2: Situações em que o adolescente se torna responsável e alcança a maturidade para tomar suas próprias decisões

\begin{tabular}{l|cc|cc}
\hline VARIÁVEL & \multicolumn{2}{|c|}{ ESCOLA PARTICULAR } & \multicolumn{2}{c}{ ESCOLA PÚBLICA } \\
\hline Votar nas eleições & $\mathbf{N}$ & $\%$ & $\mathbf{N}$ & $\%$ \\
Sim & 21 & 60 & 21 & 60 \\
Não & 14 & 40 & 14 & 40 \\
Retirar CNH & & & & \\
Sim & 15 & 42,9 & 16 & 45,7 \\
Não & 20 & 57,1 & 19 & 54,3 \\
Casar e ter filhos & & & & \\
Sim & 04 & 11,4 & 11 & 31,4 \\
Não & 31 & 88,6 & 24 & 68,6 \\
Escolher profissão & & & & \\
Sim & 23 & 65,7 & 26 & 74,3 \\
Não & 12 & 34,3 & 09 & 25,7 \\
Prestar Vestibular/ Concurso Público & & & & \\
Sim & 30 & 85,7 & 23 & 65,7 \\
Não & 05 & 14,3 & 12 & 34,3 \\
\hline
\end{tabular}

Verificou-se que $60 \%$ dos estudantes de ambas as escolas concordaram que os adolescentes já são capazes escolher um candidato para representá-los nas eleições. No quesito escolha da profissão, os estudantes de ambas as escolas concordam que o adolescente já estaria amadurecido para tal decisão $165,7 \%$ do ensino particular; com mais $74,3 \%$ do ensino público). No tocante a prestar vestibular ou concurso público, $85,7 \%$ dos estudantes da rede particular disseram concordar com a capacidade dos adolescentes para exercer tais atividades, juntamente com $65,7 \%$ dos estudantes rede pública.

No que concerne a experiência de vida dos jovens com a criminalidade, investigou-se se eles já haviam sido submetidos a alguma medida socioeducativa e se eles conheciam alguém que também já havia cumprido tais medidas, como também a que tipo de medidas foram julgados. Verificou-se que apenas um adolescente da rede de ensino pública confirmou ter recebido uma advertência como medida socioeducativa. Já 82,9\% dos estudantes, também da rede pública, informaram que conheciam algum jovem que cumpriu ou cumpre alguma medida, contra $71,4 \%$ dos estudantes da rede de ensino privado. A internação foi o tipo de medida mais aplicada a esses jovens, e o motivo pelo qual cumpriu, que apareceu com mais frequência foi o roubo ou furto, na escola particular, e o tráfico de drogas na escola pública. 
Tabela 3: Envolvimento dos adolescentes com a criminalidade

\begin{tabular}{l|cc|cc}
\hline VARIÁVEL & \multicolumn{2}{|c|}{ ESCOLA PARTICULAR } & \multicolumn{2}{c}{ ESCOLA PÚBLICA } \\
\hline Cumpriu medida & $\mathbf{N}$ & $\%$ & $\mathbf{N}$ & $\%$ \\
Sim & ---- & ---- & 01 & 2,9 \\
Não & 35 & 100 & 34 & 97,1 \\
Alguém conhecido & & & & \\
Sim & 10 & 28,6 & 06 & 17,1 \\
Não & 25 & 71,4 & 29 & 82,9 \\
Tipo de medida & & & & \\
Advertência & 03 & 30 & 01 & 16,7 \\
Prestação de serviços & 02 & 20 & ----- & ----- \\
Liberdade assistida & 01 & 10 & ----- & ------ \\
Semi liberdade & 02 & 20 & 01 & 16,7 \\
Internação & 02 & 20 & 04 & 66,7 \\
Tipo de infração & & & & \\
Não lembra & 01 & 10 & 01 & 16,7 \\
Tráfico de drogas & ----- & ---- & 03 & 50 \\
Roubo/furto & 05 & 50 & 02 & 33,3 \\
Homicidio & 02 & 20 & ---- & ----- \\
Porte ilegal de arma & 02 & 20 & ----- & ---- \\
\hline
\end{tabular}

A segunda parte da análise preocupou-se em trabalhar as percepções dos estudantes a partir de um universo de significados, motivos, aspirações, crenças, valores e atitudes que, por sua vez, correspondem a um espaço mais profundo das relações, a ideologia que o sujeito manifesta por meio do seu discurso, de acordo com a técnica de análise de conteúdo de Bardin (2009). Diante das respostas obtidas, o conteúdo foi organizado em categorias e em subcategorias que nortearam de forma mais eficaz a referida análise.

Tabela 4: Percepções dos estudantes acerca da maioridade penal

\begin{tabular}{|c|c|c|c|}
\hline & & ESTUDANTES DA REDE PÚBLICA & ESTUDANTES DA REDE PRIVADA \\
\hline CLASSE TEMÁTICA & CATEGORIAS & SUBCATEGORIAS & SUBCATEGORIAS \\
\hline $\begin{array}{l}\text { PERCEPÇÃO DOS } \\
\text { ADOLESCENTES } \\
\text { SOBRE A } \\
\text { MAIORIDADE }\end{array}$ & 1. A FAVOR & $\begin{array}{l}\text { 1. Adequação das Leis/Impunidade } \\
\text { 2. Responsabilização } \\
\text { 3. Redução da violência } \\
\text { 4. Negação da adolescência } \\
\text { 5. Punição como aprendizagem }\end{array}$ & $\begin{array}{l}\text { 1. Adequação das Leis/Impunidade } \\
\text { 2. Responsabilização } \\
\text { 3. Redução da violência } \\
\text { 4. Negação da adolescência }\end{array}$ \\
\hline PENAL & 2. CONTRA & $\begin{array}{l}\text { 1. Redução gradativa da } \\
\text { maioridade penal } \\
\text { 2. Proposta de redução a partir dos } \\
\text { 12 anos } \\
\text { 3. Entrada para a escola do crime }\end{array}$ & $\begin{array}{l}\text { 1. Redução gradativa da maioridade } \\
\text { penal } \\
\text { 2. Sistema penitenciário insatisfatório } \\
\text { 3. Ressocialização inadequada } \\
\text { 4. Falta de maturidade }\end{array}$ \\
\hline
\end{tabular}

A respeito do posicionamento dos estudantes sobre da proposta de redução da maioridade penal, conseguiu-se identificar duas categorias, com variações no que concerne às subcategorias, sendo 08 para os estudantes 
da rede pública e 08 para os estudantes da rede privada, conforme descrito na Tabela 4.

\section{DISCUSSÃO}

A maioria dos participantes da presente pesquisa, de ambas as escolas, afirmou ser favorável à redução e, portanto, enxergam a questão como algo positivo para a sociedade. Esse posicionamento também foi demonstrado por brasileiros adultos que participaram da pesquisa Datafolha divulgada em janeiro de 2019 pelo jornal Folha de São Paulo que constatou que 84\% destes eram favoráveis à redução da maioridade penal de 18 para 16 anos. Segundo os dados, $14 \%$ eram contrários à alteração da lei e $2 \%$ eram indiferentes ou não opinaram. A coleta dos dados ocorreu em 130 municípios distintos e contou com uma amostra de 2.077 pessoas.

Sobre a maioridade penal, a dúvida acerca do juízo feito por um jovem de 16 anos ao cometer uma ação criminosa é frequente, questionando-se até que ponto o adolescente teria desenvolvido maturidade para assumir responsabilidades. Com relação a esse fato, os estudantes de ambas as escolas afirmaram que nessa idade o sujeito não estaria preparado para casar e ter filhos e nem retirar a CNH. Porém, já estariam amadurecidos para prestar vestibular ou concurso, escolher uma profissão e votar nas eleições, demonstrando aptidão plena nas escolhas individuais que envolvem raciocínio e discernimento pessoal.

Sobre essa questão, Oliveira e Sá (2008) ressaltam que a Constituição Federal de 1988 atribuiu maturidade ao jovem de 16 anos de idade, principalmente quanto ao direito de voto, mesmo facultativo. Com isto, se tornam capazes de eleger seus representantes políticos, e decidir sobre os interesses de toda a nação brasileira. Também é concedida pela justiça a emancipação aos 16 anos de idade, atentando para o fato de que o jovem amadurece mais cedo, podendo casar, constituir um lar e manter a educação e criação dos filhos, inclusive podendo ser proprietário de empresa e gerenciá-la.

No entanto, o Conselho Federal de Psicologia (CFP, 2017) tem assumido posição contrária à redução da maioridade penal. Dentre as justificativas, o CFP destaca principalmente aspectos como: as peculiaridades dos diferentes momentos do desenvolvimento humano, uma vez que o desenvolvimento de cada sujeito ocorre em um contexto relacional, social e histórico, e a compreensão de suas condutas não pode se dar com base em uma perspectiva individualista. Além disso, argumenta que a perspectiva educativa é norteadora do desenvolvimento humano saudável, em oposição às perspectivas punitiva e repressiva.

Para o CFP (2017) a responsabilidade do Estado brasileiro no fracasso da garantia dos direitos fundamentais de crianças e adolescentes deve ser considerada como entrave ao desenvolvimento saudável de crianças e adolescentes. Compreende também que a leitura equivocada do ECA leva à confusão entre 
"inimputabilidade" e "impunidade" e que reduzir a idade penal é tratar os efeitos e não a causa do problema, haja vista que a violência não será solucionada por culpabilização e punição do sujeito do ato, mas, antes, pela ação nas instâncias psíquicas, sociais, políticas e econômicas que a produzem.

Ao investigar as experiências de vida desses adolescentes com a criminalidade, apenas um estudante da rede pública cumpriu medida socioeducativa, porém os estudantes da rede particular conheciam mais jovens que cumpriram algum tipo de punição. Tal fato traz a reflexão de que o problema da violência entre os jovens demanda de qualquer um dos horizontes. Sejam para aqueles que possuam ou não, condições de ter sua educação custeada ou que estejam inseridos em domicílios localizados em bairros da periferia ou considerados zona nobre. A problemática do adolescente em conflito com a lei é complexa, tendo em vista que a prática de atos infracionais envolve uma diversidade de fatores, além de diversos posicionamentos que não podem ser contemplados somente sob uma ótica ou disciplina (VAZ; MOREIRA, 2015).

Apesar de a violência permear a vivência de muitos dos adolescentes participantes, o perfil do jovem que cumpre medida socioeducativa no país, de acordo com o mapeamento do Instituto de Pesquisa Econômica Aplicada - IPEA (2002) e da pesquisa Panorama Nacional - A Execução das Medidas Socioeducativas de Internação, realizada pelo Conselho Nacional de Justiça (CNJ) realizada em 2012, são jovens que não possuem uma estrutura familiar adequada, que pertencem a classe social baixa, de etnia afro descendente, com baixos índices de escolaridade e que apresentam envolvimento com drogas. Percebe-se, portanto, que a temática dos atos infracionais cometidos por adolescentes é um problema amplo, assim como os demais problemas de ordem social. Volpi (2001) destaca a existência de uma multidiversidade de fatores que ocorrem de forma complexa e de difícil isolamento.

Diante do discurso dos estudantes de ambas as escolas, constatou-se que os mesmos compreendem o projeto de rebaixamento da maioridade penal como necessário para a sociedade, e foi apontado pelos estudantes da rede pública como uma questão ligada a impunidade (...nossas leis são muito brandas, ...eles sempre saem fácil da cadeia, ...eles cometem algum crime e não "pagam" pelo que fizeram, (... a lei está a favor deles, ...a lei "passa a mão em suas cabeças"), enquanto que para os estudantes da rede privada é uma questão de adequação da ordem constitucional (...era para ser igual a do EUA, crianças de 12, 10 anos já é condenada a morte, ...se for como nos EUA, seria perfeito).

Observa-se na fala dos adolescentes, que o grau de confiança da população na própria justiça, não é dos mais elevados. Segundo Waiselfisz (2013), apenas uma pequena porcentagem dos crimes é resolvida no Brasil, gerando assim, uma baixa credibilidade nos sistemas de segurança. A construção da impunidade segundo Faleiros (2004) se dá porque tanto as pessoas como o aparelho judiciário separam 
a justiça da aplicação do direito e como vive-se numa sociedade desigual, as pessoas também são tratadas de maneira diferente. Além disso, Santibanez, Frattari e Oliveira (2015) afirmam que a mídia tem preferência por veicular fatos criminais em que há participação de adolescentes, frequentemente chamados de "menores", mencionando, geralmente, a necessidade de redução da maioridade penal ao noticiar crimes cuja autoria é de adolescentes.

A impunidade é construída numa dinâmica da relação de forças que imuniza o dominante pelo poder que exerce perante o Estado, na destinação de recursos, na troca de favores, no uso da força para calar as denúncias; uma avalanche de Comissões Parlamentares de Inquéritos mal acabadas. Pessoas que se sentem exclusas dos direitos, também se sentirão exclusas de seus deveres, fazendo surgir uma crise moral. Como todo direito fundamental, a inimputabilidade penal não pode ser extirpada da Constituição Brasileira, pois se trata de cláusula pétrea, imutável dentro da ordem jurídica, portanto não há possibilidade de Emenda Constitucional (DEVECHI, 2007). Com isso, essa modificação na lei que os adolescentes almejam, não pode ser deliberada, pois se trata de uma questão inconstitucional.

A redução da maioridade penal como uma questão de responsabilização do adolescente pelos seus atos, também foi evidenciada pelos dois grupos, que são a favor da causa, seja mais relacionada às responsabilidades que o adolescente já pode assumir, seja pela culpabilização de seus atos (...já que o indivíduo tem a consciência de fazer o ato ele tem que se responsabilizar, ... qualquer pessoa com seus 15 nos sabe muito bem o que faz. Sabe o que é certo e o que é errado, ...se tem idade de roubar e matar, acho que também tem idade de ser preso, ...aos 16 anos já era pra ser preso eles já sabem o que é certo e o errado).

Curiosamente, percebe-se que as falas dos participantes se referem aos adolescentes como "eles" e não como "nós", como se ambos não formassem um mesmo grupo. Apesar disso, os argumentos apresentados pelos participantes corroboram com Reale (2011) que afirma que atualmente os adolescentes tem acesso a muitas informações, o que faz com que eles tenham consciência da ilicitude de seus atos mais cedo. Ressalta ainda que se o adolescente sabe que se praticar um ato infracional ficará impune, por si só estará justificada a necessidade da redução da maioridade penal.

Segundo Campos (1990), o adolescente baseia seu comportamento mais naquilo que as pessoas fazem do que naquilo que elas dizem, portanto seguem modelos. Ainda segundo a autora, é na adolescência que a base relação de causa e efeito começa a ser construída, já tendo mais ou menos definida suas aptidões intelectuais. Com isso, percebe-se que sua maneira de ver o mundo ainda sofre mudanças, incriminando assim, suas possibilidades mentais.

No que concerne a redução da maioridade penal como a estratégia de redução da violência, ambos os grupos informaram que essa tomada reduziria 
a prática de crimes cometidos nessa faixa etária (...uma boa forma de diminuir a evidência dos assaltos, ...vai melhorar muito a questão da violência no Brasil, ...poderia ajudar a diminuir a violência onde vivemos, ...é uma forma de inibir mais, ou de dar mais segurança a todos nós, ...diminuir esses delitos, ...tentar amenizar a bandidagem de hoje em dia). Segundo Cunha, Ropelato e Alves (2006), o simples fato de encarcerar não é capaz de evitar que o adolescente possa praticar crimes futuros, pois aprisionar não possui caráter educativo. De maneira contrária à opinião dos adolescentes participantes, Arantes (2013) afirma que o rebaixamento da idade penal terá pouco impacto sobre os índices de criminalidade, uma vez que a maioria dos crimes é praticada por adultos. Descreve ainda que a situação de violência que estamos vivenciando é fruto de um longo e complexo processo histórico.

Em relação à redução da maioridade penal sob o aspecto da negação da adolescência, os estudantes de ambas as escolas demonstram que o fato dessa faixa etária possuir certas peculiaridades no seu desenvolvimento, não sobressai na hora dele ser julgado por um ato de infração (...qualquer um que cometa um crime deve ser julgado igualmente independente de ser adolescente ou não, ...não tem idade para pagar pena se fez algo de errado e não importa se é adolescente). Os participantes entendem, portanto, que os adolescentes são plenamente conscientes de suas ações, apesar da atual legislação não os considerar dessa forma. Tais dados corroboram com Lins, Figueiredo Filho e Silva (2016) que afirma que uma vez constatada a maturidade intelectual e emocional do agente, este deve ser penalmente responsabilizado por suas ações e/ou omissões.

Ainda sobre a Categoria "A favor", emergiu apenas para os estudantes da rede pública uma subcategoria que trata a redução da maioridade penal como uma questão de aprendizagem, por meio da punição (...para que os jovens aprendam um pouco, como é ruim ficar preso, ....seria ótimo para os jovens, poderiam se conscientizar mais de suas atitudes como cidadão).De forma semelhante, o estudo realizado por Santibanez, Frattari e Oliveira (2015) constatou discursos, de um modo geral, quase sempre ressaltando a necessidade de punição rigorosa com relação aos atos ilícitos praticados por adolescentes. As falas dos participantes dessa pesquisa enfocavam a questão da responsabilidade imputada ao jovem aos 16 anos, uma vez que este é considerado apto a exercer a cidadania por meio do voto e que, consequentemente, deve ser passível de punição legal caso se envolva na prática criminal. Muitas narrativas enfocavam também a comodidade da prática delituosa por adolescentes em função do conhecimento da não imputabilidade penal que lhes é garantida por lei.

De acordo com Teixeira (2013), a punição surge como um mecanismo central ao controle e quando aquela penalidade não é suficiente, então, necessita-se de mais punição para se controlar o que está errado. Para Skinner (2003), a punição pode surgir como um reforçador na aprendizagem humana que pode diminuir a 
probabilidade futura de um comportamento ruim. Nesse caso, ao saber que vai ser severamente punido, o adolescente não cometerá mais crimes.

Em relação aos aspectos contrários à proposta de redução da maioridade penal, os estudantes constataram que esta não seria uma boa solução para resolver o problema. Ficou evidenciado pelos jovens de ambas as instituições que um dos impedimentos seria o acontecimento de uma redução gradativa da maioridade penal (...vão acabar baixando para 10 anos de idade mais nada vai adiantar, ...todos os adolescentes que estiverem abaixo da maioridade penal eles passarão a roubar e praticar delitos, ...cada vez mais novos serão recrutados para o crime). Em consonância com a fala dos participantes, Sankievicz (2007) afirma que a lógica da redução penal está errada e pode trazer consequências ruins à sociedade. Segundo ele, o rebaixamento da idade para a imputabilidade penal certamente não diminuirá a criminalidade e diz que se for reduzida, daqui a pouco uma criança de dez anos vai começar a ser utilizada pelas quadrilhas e assim por diante.

Especificamente no discurso dos alunos da rede pública constatou-se uma modalidade diferente de proposta de redução da maioridade penal. Alguns participantes afirmaram que a proposta não deveria ser reduzida para 16 anos e sim para 12. Essa subcategoria não indica uma posição desfavorável à aprovação do projeto, e sim um desejo mais rigoroso da modificação da proposta. (...tem que mudar a proposta de 16 anos para 12,...deveria ser a partir dos 12 anos ou nessa faixa). Para Devechi (2007) em países como os Estados Unidos a fixação da idade é muito mais baseada em parâmetros de política criminal do que em critérios científicos. $O$ autor declara ainda que nos países onde a idade penal é menor, antes de ver um policial os adolescentes conhecem professores e pais com emprego. Ou seja, são realidades diferentes e, portanto, merecem também legislação diferenciada.

Outra categoria indicou ainda que os estudantes temem que o jovem que cometeu infração possa entrar para a escola do crime (...a partir do momento que são presos ou apreendidos saem pior do que entraram, ...iriam aprender na cadeia, crimes piores). Para Arantes (2013) o rebaixamento da idade penal colocará o adolescente em contato com grupos organizados e criminosos mais velhos e experientes, diminuindo suas chances de não reincidência e de conclusão dos estudos e profissionalização. Segundo a autora, haveria um movimento contrário, que ao invés de regredir a prática de crimes, fará com que o indivíduo se especialize no assunto, corroborando com a fala dos participantes.

Para os estudantes da rede particular surgiram outras subcategorias como: sistema penitenciário insatisfatório (....se as prisões estivessem adequadas, .... sistema penitenciário do Brasil é muito escasso, .... sistema carcerário atual simplesmente não suporta a consolidação desta proposta), ressocialização inadequada (...enquanto que não existir projetos de ressocialização, não vai adiantar nada, ...a educação é o único caminho para melhorar essa situação, daqui a uns 04 anos estará solto, e não terá aprendido nada) e falta de maturidade (...mesmo que diminua, eles não 
terão amadurecido o bastante, ...um adolescente de 16 anos não tem ideia do crime que está cometendo) .

É fato que as prisões brasileiras estão longe de ser um modelo. Recuperar detentos ainda é um desafio para nosso sistema penitenciário. Conforme levantamento do Banco Nacional de Monitoramento de Presos (2018) existem atualmente no Brasil 602.217 presos, dos quais $95 \%$ são homens e 5\% são mulheres. Cerca de $40 \%$ são presos provisórios e $27 \%$ respondem por roubo. Os dados mostram também que há mais presos do que vagas no sistema. São 368.049 vagas em 1.449 unidades penais em todo o território nacional: a maioria são penitenciárias, casas de custódia e unidades de semiliberdade administradas pelos governos estaduais.

Sem contar que quando um adolescente ingressa numa instituição, ele recebe o rótulo de infrator, de delinquente ou de marginal, e sai de lá com mínimas chances para mudar de vida (GOMIDE, 1988). A autora ainda declara que assim como um paciente internado em uma Instituição Psiquiátrica, o infrator é afastado do contato com outros meninos de sua idade não-infratores e, consequentemente, expostos a um "código de valores internos" cuja aceitação facilita a sua adaptação à vida da Instituição. Como em qualquer grupo, os novos membros aprendem as regras e a cultura geral da comunidade para serem aceitos. E como o adolescente ainda se encontra num processo de construção da sua identidade, ele internaliza as influências do seu grupo e se transforma naquilo que o grupo deseja.

\section{CONSIDERAÇÕES FINAIS}

O presente estudo analisou as percepções dos adolescentes acerca da maioridade penal, sendo possível identificar semelhança no que concerne ao posicionamento favorável à redução da maioridade penal. Divergências, entretanto, foram constatadas no grupo que assumiu postura contrária à redução. As diferenças foram perceptíveis nas justificativas apresentadas pelos adolescentes, onde entre os estudantes da rede pública emergiu o argumento de que se o projeto fosse aprovado certamente os adolescentes iriam se especializar na escola do crime, o que viria a piorar a situação. Já os estudantes da rede particular teceram críticas aos meios de ressocialização atualmente, bem como ao sistema prisional considerado insatisfatório, e ainda perceberam a falta de maturidade que compreende essa fase da vida do sujeito.

A respeito das experiências de vida dos adolescentes com a criminalidade, os resultados demonstraram que a violência emana dentre os que disseram ter renda média familiar de um salário mínimo ou dez, representando que o crime permeia a vida de toda a sociedade e não apenas os menos favorecidos economicamente. Ademais, os estudantes da rede particular informaram conhecer mais adolescentes em conflito com a lei do que os participantes da rede pública de ensino. 
A maioridade penal propicia questionamentos que vão muito além da redução da idade do jovem infrator. A criança e o adolescente que atualmente ingressam no mundo do crime perdem mais do que sua própria liberdade, perdem sua infância/adolescência, seus sonhos, enfim, perdem sua esperança de um futuro melhor. Ao Estado cabe oferecer melhoria em políticas públicas a favor desses jovens para que tenham estrutura e oportunidades e assim afastá-los da prática de atos ilícitos.

Ademais, cabe também destacar que um dos maiores obstáculos foi a limitação de pesquisas sob a ótica do adolescente. Apesar de ser um tema atual e polêmico, que se reflete na vida dos jovens brasileiros, se constata a escassez de pesquisas que fomentem o assunto e que investiguem a percepção dos próprios adolescentes. Portanto, ressalta-se que este foi um estudo inovador, sendo pouco encontrado na literatura, no tocante ao olhar do adolescente nesse sentido.

É perceptível e legítimo o clamor da população por justiça e o desejo de que a impunidade acabe no país, porém é válido ressaltar que limitar a problemática da violência e da criminalidade apenas a redução da maioridade penal é uma visão simplista e equivocada do problema. Diante desse cenário, esse estudo representa um elemento a mais para subsidiar o entendimento da questão, sem, entretanto, tomar algum posicionamento contrário ou favorável ao projeto, como também, esgotar os conteúdos. A psicologia como ciência e profissão, muito tem a contribuir a partir de um diálogo plural, intersetorial e interprofissional, unindo forças para pensar estratégias e articulações que criem condições para a mudança esperada.

Embora a maioria dos participantes tenha demonstrado parecer favorável à redução da maioridade penal, muitos ressaltaram que a alternativa à violência juvenil estaria na ampliação das atividades do sistema educacional e na total reformulação do sistema de internação de adolescentes em conflito com a Lei. Entendem, portanto, que é necessário mudar a legislação para que os adolescentes de 16 a 18 anos cumpram penas no sistema prisional, porém recebendo a atenção psicossocial adequada. A prisão não pode ser vista como a salvação, uma vez que se tratando do sistema prisional brasileiro, sabe-se que o mesmo é tido como ineficaz e ausente de sua função educativa, o que seria de fato importante para o bom desenvolvimento do jovem para livrá-lo de possíveis reincidências.

\section{REFERÊNCIAS}

ALVES. A. C. O crime só inclui quando o estado exclui! In: CONSELHO FEDERAL DE PSICOLOGIA (CFP). Redução da idade penal: Socioeducação não se faz com prisão. p. 35-37, 2013. 
ANDI. Adolescentes em conflito com a lei: Guia de referência para a cobertura jornalística. Série Jornalista Amigo da Criança. Realização: ANDI - Comunicação e Direitos. Apoio: Secretaria de Direitos Humanos da Presidência da República, 2012.

ARANTES, E. M. M. Sobre as propostas de redução da maioridade penal. In: CONSELHO FEDERAL DE PSICOLOGIA (CFP). Redução da idade penal: Socioeducação não se faz com prisão. p. 9-13, 2013

BARDIN, L. Análise de Conteúdo. Lisboa, Portugal; Edições 70, LDA, 2009.

BOCK, A. M. B. A perspectiva sócio-histórica de Leontiev e a crítica à naturalização da formação do ser humano: a adolescência em questão. Cad. Cedes, Campinas, n. 62, v-24, p. 26-43, 2007.

BRASIL. Conselho Nacional de Saúde. Resolução $n^{\circ}$ 466, de 12 de dezembro de 2012. Aprova diretrizes e normas regulamentadoras de pesquisas envolvendo seres humanos e revoga também as Resoluções n³03/2000 e n 404/2008.

BRASIL. Constituição (1988). Constituição da República Federativa do Brasil: promulgada em 05 de outubro de 1988. Disponível em: <http://www.planalto.gov. br/ccivil_03/constituicao/constituicao.htm>. Acesso em: 22 mar 2014.

BRASIL. Estatuto da Criança e do Adolescente. Lei Federal n 8069, de 13 de julho de 1990. Ministério Público do Estado do Paraná. Centro de Apoio Operacional das Promotorias da Criança e do Adolescente. Curitiba, 6 ed, 2013.

BRASIL. Portal da Câmara dos Deputados. Comissão para analisar redução da maioridade penal. Brasília, 2013. Disponível em: <http://www2.camara.leg.br>. Acesso em: 03 abr 2014.

BRASIL. Portal Agência Senado. Comissões de Constituição e Justiça. Redução da maioridade penal pode entrar na pauta da CCJ. Disponível em: <http://mww12.senado. gov.br/noticias/materias/2013/01/1 1/reducao-da-maioridade-penal-pode-entrar-na-pautada-ccj>. Acesso em: 25 out 2014.

BRASIL. Proposta de Emenda à Constituição - PEC n²28, de 2012. Altera o art. 228 da Constituição Federal, para reduzir a idade prevista para imputabilidade penal, nas condições que estabelece. Disponível em: <http://www.camara.gov.br/ proposicoesWeb/prop_mostrarintegra? codteor=1049245\&filename=PEC+228/2012>. Acesso em: 03 abr 2014. 
BRASIL. Requerimento $n^{\circ}$ 9097, de 20 de novembro de 2013. Relatoria da Comissão de Justiça e Cidadania da Câmara dos Deputados. Requer desapensação de matéria PEC 349, de 2013 à PEC 332, de 2013, consequentemente à PEC 171, de 1993. Disponível em: <http://www.camara.gov.br/proposicoesWeb/ fichadetramitacao; jsessionid=1 BC3E4579 C6BF62F45045618EAD5B7A 1 . node2?idProposicao=601661>. Acesso em: 03 abr 2014.

BRASIL. Sistema Nacional de Atendimento Socioeducativo (SINASE). Brasília: Conselho Nacional dos Direitos da Criança e do Adolescente (CONANDA), 2006.

CAMARANO, A. A.; MELLO, J. L.; KANSO, S. Semelhanças e diferenças nas transições ao longo do ciclo da vida por regiões e cor/etnia. In: CAMARANO, A. A. (Org.). Transição para a vida adulta ou vida adulta em transição? Rio de Janeiro: Ipea, p. 61-96, 2006.

CAMPOS, D. M. S. Psicologia da adolescência: normalidade e psicopatologia. 12 ed. Petrópolis: Vozes, 1990.

COLOMBAROLLI, M.S. et al. Proposta de redução da idade penal: visão dos profissionais da psicologia. Psicologia Argumento. v. 32, n. 77, p. 19-26, abr./jun. 2014.

CONSELHO FEDERALDEPSICOLOGIA (CFP). Redução da idade penal:Socioeducação não se faz com prisão. p. 52, 2013.

CONSELHO FEDERAL DE PSICOLOGIA (CFP). Manifestação Contrária à Pec 33/2012. 19 de setembro de 2017. Disponível em: https://site.cfp.org.br/wp-content/ uploads/2017/09/manifesto-contrario-a-pec-33-2012-2.pdf. Acesso em: 19 de maio de 2019.

CONSELHO NACIONAL DE JUSTIÇA. Panorama Nacional - A Execução das Medidas Socioeducativas de Internação. Programa Justiça ao Jovem, Brasília, 2012.

CONSELHO NACIONAL DE JUSTIÇA. Banco Nacional de Monitoramento de Prisões - BNMP 2.0: Cadastro Nacional de Presos, Conselho Nacional de Justiça, Brasília, agosto de 2018.

CHIUZI, R. M.; PEIXOTO, B. R. G.; FUSARI, G. L. Conflito de gerações nas organizações: um fenômeno social interpretado a partir da teoria de Erik Erikson. Temas em Psicologia. Ribeirão Preto, n. 2, v-19, Dez. 2011.

CUNHA, P. I.; ROPELATO, R.; ALVES, M. P. A Redução da Maioridade Penal: Questões Teóricas e Empíricas. Psicologia: Ciência e Profissão, n. 26, v-4, 646-659, $2006 .$. 
DEVECHI, J. C. C. Maioridade Penal: Razões para sua manutenção em 18 anos completos. 2007. 90 f. Curso de Preparação à Magistratura (Especialização). Escola de Magistratura do estado do Paraná. Curitiba, 2007.

ERIKSON, E. H. Infância e Sociedade. 2 ed. Rio de Janeiro: Zahar, 1987.

ERIKSON, E. H. Identidade, juventude e crise. ed. Rio de Janeiro: Zahar, 1972.

FALEIROS, V.P. Impunidade e inimputabilidade. Serviço Social \& Sociedade. São Paulo, ano 24, n. 77: Cortez, abril de 2004.

FORMIGLI, V. L. A.; COSTA, M. C. O.; Porto, L. A. Avaliação de um serviço de atenção integral à saúde do adolescente. Cadernos de Saúde Pública, v. 16, p.831-841, 2000.

FREUD, S. (1905). Três Ensaios sobre a Teoria da Sexualidade. Trad. De Paulo Dias Correa. Rio de Janeiro, Imago, 1989. Edição Standard Brasileira das Obras Psicológicas Completas de Sigmund Freud. v. 07, 1905.

GOMIDE, P. I. C. A instituição e a identidade do menor infrator. Psicologia: Ciência e Profissão. Brasília, n. 1, v- 8, 1988 . Disponível em: <http://www.scielo.br/scielo. php?script=sci_arttext\&pid=S1414-98931988000100013\&lng=en\&nrm=iso>. Acesso em: 15 nov 2014.

INSTITUTO DE PESQUISA ECONÔMICA APLICADA (IPEA). Boletim Mercado de Trabalho - Conjuntura e Análise n 53, Novembro de 2012. Disponível em: <http://www.ipea. gov.br/portal/index.php? option=com_content\&view=article\&id=16335\&ltemid=9>. Acesso em: 26 mar 2014.

INSTITUTO DE PESQUISA DATAFOLHA. Violência, PO813983. 18 e 19/12/2018. dezembro de 2018. Disponível em: http://media.folha.vol.com.br/ datafolha/2019/01/14/15c9badb875e00d88c8408b49296bf94-v.pdf. Acesso em: 19 de maio de 2019.

LINS, R.; FIGUEIREDO FILHO, D.; SILVA, L. A redução da maioridade penal diminui a violência? Evidências de um estudo comparado. Opinião Pública, v. 22, n. 1, abril, 2016

OLIVEIRA, M. C; SÁ, M. M. Redução da maioridade penal: Uma abordagem jurídica. 2008. 36 f. Trabalho de Conclusão de Curso (Especialização). Centro de estudos sociais aplicados. Curso de especialização em formulação e gestão de Políticas públicas, Londrina, 2008.

OLIVEIRA, C.; SIMÂO, L. P. A importância da inserção do aprendiz no mercado de trabalho. Revista Faculdade Montes Belos, v. 5, n. 1, Mar. 2012 
ORGANIZAÇÃO MUNDIAL DE SAÚDE (OMS). Saúde para a Adolescentes do mundo: Uma segunda chance na segunda década. Genebra, 2014. Disponível em: <http:// www.who.int/maternal_child_adolescent/topics/adolescence/second-decade/ en/>. Acesso em: 20 mai 2014.

PEREIRA, C. C. A redução da maioridade penal. Presidente Prudente: Faculdade de Direito de Presidente Prudente, p. 72 , 2012..

PESSANHA, J. L. B. Redução da Maioridade Penal: Esse é o caminho? Rio de Janeiro: Escola da Magistratura do Estado do Rio de Janeiro, p. 27, 2009.

REALE, M. Nova Fase do Direito Moderno. São Paulo: Saraiva, 2011.

ROSA, M. Psicologia evolutiva: psicologia da adolescência. 6 ed. Petrópolis: Vozes, 1990.

RUZANY, M. H. Atenção à Saúde do Adolescente: Mudança de Paradigma. In: BRASIL. Ministério da Saúde. Saúde do Adolescente: competências e habilidades. Departamento de Ações Programáticas Estratégicas. Editora do Ministério da Saúde. Brasília, 2008.

SANKIEVIC, A. Breve análise sobre a redução da maioridade penal como alternativa para a diminuição da violência juvenil. Câmara dos Deputados, p. 17, 2007.

SANTIBANEZ, D. A.; FRATTARI, N.; OLIVEIRA, D. As narrativas do medo e a criminalização da juventude: o discurso punitivo contra adolescentes em conflito com a lei. Revista Inter Ação, v.40, n.2, p.307-325, 2015.

TEIXEIRA, M. L. T. Redução da idade penal...mais uma vez! In: CONSELHO FEDERAL DE PSICOLOGIA (CFP). Redução da idade penal: Socioeducação não se faz com prisão. p. 19-212013.

SKINNER, B. F. Sobre o behaviorismo. São Paulo: Cultrix, p. 33-63; 163-176, 2003.

VAVASSORI, M.B.; TONELI, M.J.F. Propostas de Redução da Maioridade Penal: a Juventude Brasileira no Fio da Navalha?. Psicologia Ciência e Profissão, Brasília, v. 35, n. 4, p. 1188-1205, 2015.

VAZ, B.G.; MOREIRA, J.S.S. Responsabilização x Responsabilidades: o adolescente autor de ato infracional e a redução da maioridade penal. Psicologia Argumento. v.33, n.82, p.346-363, 2015.

VERÍSSIMO, R. Desenvolvimento psicossocial (Erik Erikson). Ed. Porto: Faculdade de Medicina do Porto, 2002. 
VOLPI, M. O Adolescente e o Ato Infracional. São Paulo: Cortez, 2001.

WAISELFISZ, J. J. Homicídios e juventude no Brasil. Juventude Viva: Mapa da Violência 2013. Secretaria Nacional de Juventude. Brasília, 2013.

Recebido em: 24/01/2019.

Aceito em: 20/05/2019. 